\title{
Gadolinium silicide/silicon composite with excellent high-rate performance as lithium-ion battery anode
}

Hiroyuki Usui ${ }^{1,2}$, Masahito Nomura ${ }^{1,2}$, Hiroki Nishino ${ }^{1,2}$, Masatoshi Kusatsu $^{3}$, Tadatoshi Murota ${ }^{3}$,

\section{Hiroki Sakaguchi ${ }^{1,2, *}$}

${ }^{1}$ Department of Chemistry and Biotechnology, Graduate School of Engineering, Tottori University, 4-101 Minami, Koyama-cho, Tottori 680-8552, Japan

${ }^{2}$ Center for Research on Green Sustainable Chemistry, Tottori University, 4-101 Minami, Koyama-cho, Tottori 680-8552, Japan

${ }^{3}$ Intelligent Chemical Group, R\&D Division, Santoku Corp., 4-14-34 Fukae-Kitamachi, Higashinada-ku, Kobe 658-0013, Japan

*Corresponding author. Tel./Fax: +81-857-31-5265; e-mail: sakaguch@ chem.tottori-u.ac.jp

Keywords: Rare-earth metal silicide, Si-based composite anode; Gadolinium silicide; Thick-film electrode; Gas-deposition method; Li-ion battery

\begin{abstract}
Novel composite materials consisted of elemental $\mathrm{Si}$ and rare-earth metal silicides, $\mathrm{Sm}-\mathrm{Si}, \mathrm{Gd}-\mathrm{Si}$, and Dy-Si, were synthesized and were evaluated for the first time as a high-performance anode material of Li-ion battery. Thick-film electrodes of the silicide/Si composites were prepared by an arc melting method and a successive gas-deposition method. Among them, the Gd-Si/Si composite electrode exhibited reversible Li-insertion/extraction reactions and the best cycling performance: the initial Coulombic efficiency was $80 \%$ and the discharge capacity at the 1000th cycle was $840 \mathrm{~mA} \mathrm{~h} \mathrm{~g}^{-1}$. In addition to this, the composite electrode delivered a superb high-rate performance with the capacity of $2100 \mathrm{~mA} \mathrm{~h} \mathrm{~g}^{-1}$ even at the high current rate of $12.0 \mathrm{~A} \mathrm{~g}^{-1}(4.8 C)$. The remarkable performances demonstrated that the gadolinium silicide is favorable to significantly enhance anode properties of Si-based composite electrodes.
\end{abstract}




\section{Introduction}

For the next-generation anodes for Li-ion batteries, silicon is a promising high-capacity material. Silicon shows a huge theoretical capacity of $3600 \mathrm{~mA} \mathrm{~h} \mathrm{~g}^{-1}$ for a fully-lithiated phase of $\mathrm{Li}_{15} \mathrm{Si}_{4}$ at a room temperature [1-3]. On the other hand, $\mathrm{Si}$ has some disadvantages as anode material: a low electronic conductivity and a slow kinetics of Li-ion diffusion. The most critical one is significant changes in its specific volume associated with the Li-insertion/extraction, leading to an accumulation of stress in $\mathrm{Si}$ and its pulverization. As a result, the capacity rapidly drops down because of losing an electrical contact between an active material and a current corrector. A forming alloy of Si and transition metal elements is one of some approaches to solve the problem. Many researchers have synthesized various anodes based on transition metal silicides, $\mathrm{Mg}_{2} \mathrm{Si}$ [4], $\mathrm{CaSi}_{2}$ [5,6], $\mathrm{TiSi}_{2}$ [7], $\mathrm{VSi}_{2}$ [8], $\mathrm{CrSi}_{2}$ [9], $\mathrm{FeSi}_{2}$ [8,10,11], $\mathrm{CoSi}_{2}$ [5,12], $\mathrm{NiSi}_{2}$ [5,8,13], and $\mathrm{MoSi}_{2}$ [9]. Since $\mathrm{Mg}$ and $\mathrm{Ca}$ are Li-active elements, $\mathrm{Mg}_{2} \mathrm{Si}$ and $\mathrm{CaSi}_{2}$ showed relatively high capacities at the first cycles. However, the reactivity with $\mathrm{Li}$ is too high for the silicide to exhibit a stable cycling performance. In contrast, metals in the other silicides are Li-inactive elements, and these silicides showed a long-term charge-discharge cycling stability though the reversible capacities were lower than about $200 \mathrm{~mA} \mathrm{~h} \mathrm{~g}^{-1}[5,8]$. The capacities are inferior to that of graphite anode in practical use. We have thus suggested that elemental $\mathrm{Si}$ still should be a main component of active material in the next-generation anodes to exert its huge theoretical capacity.

For a compatible performance of a high capacity and a stable cyclability, we have produced composite thick-film electrodes composed of elemental $\mathrm{Si}$ and other active materials which can compensate silicon's disadvantages [8,14-17]. As the combined active materials, we investigated various transition metal silicides, TiSi2, VSi2 [8,16], CrSi2, FeSi2 [8,16], NiSi2 [8,16], Cu-Si, LaSi2 [14,15,17], and MmSi2 [16] (Mm called cerium-rich misch metal, an alloy of light rare-earth elements). It has been demonstrated that the performance of some composite electrodes can be significantly improved by the synergetic effects of the properties of the silicides and $\mathrm{Si}$. We have revealed that these silicides have a favorable mechanical property to release the stress generated in Si particle during its lithiation/delithiation, and that they considerably improve the electrical conductivity of the composite electrode. Among these silicides, the composite electrodes of $\mathrm{LaSi}_{2} / \mathrm{Si}[14,15,17]$ and $\mathrm{MmSi}_{2} / \mathrm{Si}$ [16] exhibited a remarkably stabilized performance. This appears to be attributed to higher thermodynamic stabilities of the rare-earth metal silicides in comparison with other transition metal silicides [16]. On the other hand, the effect of other rare-earth metal silicides on the performance has never explored yet. In this study, we chose samarium, gadolinium, and dysprosium as rare-earth elements to be silicides because these elements are relatively available in middle and heavy rare-earth elements. We prepared new composite thick-film electrodes composed of these silicides and elemental $\mathrm{Si}$, and investigated the anode properties of the composite electrodes for the first time.

\section{Experimental details}

Composite active materials, composed of rare-earth metal silicides and elemental Si, were synthesized by an arc melting method [18]. A mixture of rare-earth metal $L n$ ( $L n: \mathrm{Sm}, \mathrm{Gd}$, and Dy) and Si was melted in an arc furnace under an Ar atmosphere, and then was cooled down to form ingots of $\mathrm{Ln}-\mathrm{Si} / \mathrm{Si}$ composites. A ratio of $\mathrm{Ln}-\mathrm{Si}$ and elemental $\mathrm{Si}$ in the resulting composites was about 30 and 70 in wt.\%. The ingots obtained were mechanically crushed by using a stamp mill to form active material powders. Crystal structure 
and chemical composition of the powders were analyzed with an X-ray diffraction (XRD) and an inductively coupled plasma-atomic emission spectroscopy. Although it was difficult to identify crystal phase for $L n-\mathrm{Si}$ because of many similar structures of $\mathrm{LnSi}_{2-x}$ [19], the XRD analysis revealed that the crystal phase of $\mathrm{Sm}-\mathrm{Si}$ in the composite is $\mathrm{SmSi}_{2}$ (Fig. S1). On the other hand, we identified Gd-Si and Dy-Si in the composites as GdSi1.85 [19,20] and DySi1.75 [19] (Figs. S2 and S3). The structure and chemical composition were summarized in Table. 1. In this study, we call hereafter these silicides $\mathrm{Sm}-\mathrm{Si}, \mathrm{Gd}-\mathrm{Si}$, and Dy-Si because we focus difference not in the crystal structure but in the rare-earth elements.

Thick-film electrodes consisting of the active material powder of these $L n-\mathrm{Si} / \mathrm{Si}$ composites were prepared on current collectors of copper foils by a gas-deposition (GD) method [21,22]. This method does not require any binder and conductive additive to prepare thick-film electrodes, which is very beneficial for evaluating an original anode property of an active material. The thick-film electrode will well reflect a property of a commercialized electrode prepared by using a slurry containing active material powder because the thick film also consist of cohesive aggregates of the powder. The weight of the active materials in the thick-film electrodes was approximately $40 \mu \mathrm{g}$, which corresponds to about $50 \mu \mathrm{g} \mathrm{cm}^{-2}$. A typical film thickness was confirmed to be $2.5 \mu \mathrm{m}$ by observation using a confocal scanning laser microscope (CSLM, VK-9700, Keyence). An elastic deformation property of silicide electrodes was measured by an indentation test using a dynamic ultra-micro hardness tester (DUH-211S, Shimadzu Co. Ltd.).

Electrode performances as a Li-ion battery anode were evaluated in a beaker-type there-electrode cell. Working electrodes were the $\mathrm{Ln}-\mathrm{Si} / \mathrm{Si}$ composite thick-film electrodes. We used Li metal sheets as counter and reference electrodes, and $1 \mathrm{M} \mathrm{LiBF}_{4} /$ propylene carbonate as the electrolyte [15,16,21,22]. Galvanostatic charge-discharge tests were carried out using an electrochemical measurement system (HJ-1001 SM8A, Hokuto Denko Co., Ltd.) at $303 \mathrm{~K}$ with potential ranges of $0.005-2.000 \mathrm{~V}$ vs. $\mathrm{Li} / \mathrm{Li}^{+}$under $3.0 \mathrm{~A} \mathrm{~g}^{-1}$. This current density corresponds to a current rate of $1.2 \mathrm{C}$. We defined $2520 \mathrm{~mA} \mathrm{~g}^{-1}$ (70\% of $3600 \mathrm{~mA} \mathrm{~g}^{-1}$, well-known theoretical capacity of $\mathrm{Si}$ ) as $1.2 \mathrm{C}$ because the $\mathrm{Ln}-\mathrm{Si} / \mathrm{Si}$ composites contain about 70 wt.\% elemental Si.

The gas-deposition and the cell assembly were performed throughout in a purge-type glove box (Miwa MFG, DBO-2.5LNKP-TS) filled with an Ar atmosphere in which an oxygen concentration and a dew point were below $1 \mathrm{ppm}$ and $-100^{\circ} \mathrm{C}$, respectively. For comparison, we prepared a $\mathrm{La}-\mathrm{Si} / \mathrm{Si}$ composite in a 30/70 weight ratio and electrodes of silicide alone ( $\mathrm{La}-\mathrm{Si}, \mathrm{Sm}-\mathrm{Si}, \mathrm{Gd}-\mathrm{Si}$, and $\mathrm{Dy}-\mathrm{Si}$ ) by using a mechanical alloying method [14,15], and evaluated the anode properties of these electrodes.

\section{Results and discussion}

Figures 1 shows constant current charge-discharge ( $\mathrm{Li}$ insertion-extraction) curves at the first cycle for the $\mathrm{Ln}-\mathrm{Si} / \mathrm{Si}$ composite thick-film electrodes. The all composite electrodes exhibited long flat plateaus started at around $0.09 \mathrm{~V}$ vs. $\mathrm{Li} / \mathrm{Li}^{+}$in the charge (lithiation) curves. The flat plateaus are the characteristic of the phase transition from crystalline $\mathrm{Si}$ to crystalline $\mathrm{Li}_{15} \mathrm{Si}_{4}$ ( $\mathrm{Li}_{3.75} \mathrm{Si}$ ) $[1,2,23,24,26]$ through amorphous $\mathrm{Li}-\mathrm{Si}$ [2,3,24-26]. In the discharge (delithiation) curves, gentle potential slopes began from about $0.3 \mathrm{~V}$ vs. $\mathrm{Li} / \mathrm{Li}^{+}$followed by long flat plateaus at approximately $0.45 \mathrm{~V}$ vs. $\mathrm{Li} / \mathrm{Li}^{+}$. The gentle slopes and flat plateaus are reported to originate from the formation of amorphous $\mathrm{Si}$ by delithiation of the amorphous $\mathrm{Li}-\mathrm{Si}[2,24]$ and the $\mathrm{Li}_{15} \mathrm{Si}_{4}$ [26], respectively. As for the composite electrodes except for $\mathrm{La}-\mathrm{Si} / \mathrm{Si}$, no remarkable 
shoulder was observed in the charge profiles at a potential higher than $0.5 \mathrm{~V}$ vs. $\mathrm{Li} / \mathrm{Li}^{+}$, whereas a reductive decomposition reaction of $\mathrm{PC}$ has been reported to occur at the potential of approximately $0.7-0.8 \mathrm{~V}$ vs. $\mathrm{Li} / \mathrm{Li}^{+}$[27]. These results indicate that flowed electrical charges were mainly expended not in the electrolyte decomposition but in the electrode reaction to form the $\mathrm{Li}-\mathrm{Si}$ alloys. The $\mathrm{Ln}-\mathrm{Si} / \mathrm{Si}$ electrodes except for $\mathrm{La}-\mathrm{Si} / \mathrm{Si}$ showed high Coulombic efficiencies of about $80 \%$. So high initial efficiency has been never achieved for any silicide-based anodes prepared by the authors [14-16] and other research groups [7,9-11,13], to our knowledge. It was clarified that a large amount of Li-insertion/extraction reversibly takes place in the case of these composite electrodes.

Figure 2 shows the variation in the discharge capacities of these composite thick-film electrodes following the increase in the number of charge-discharge cycles. For comparison, the capacities of a thick-film electrode of $\mathrm{Si}$ alone are also plotted in the figure. In contrast with the Si electrode showing a quick capacity decay caused by its pulverization, the all composite electrodes exhibited improved performances. In particular, the $\mathrm{Gd}-\mathrm{Si} / \mathrm{Si}$ electrode maintained a very large discharge capacity of $840 \mathrm{~mA} \mathrm{~h}$ $\mathrm{g}^{-1}$ even after 1000 cycles, which clearly demonstrating its distinctly excellent performance. The discharge capacity of $\mathrm{Gd}-\mathrm{Si} / \mathrm{Si}$ is much larger than the graphite's theoretical capacity of $372 \mathrm{~mA} \mathrm{~h} \mathrm{~g}^{-1}$. This performance is attributed to a suppressed disintegration of its active material layer, which is supported by surface morphology observation (Fig.S4). On the other hand, the electrodes of $\mathrm{Sm}-\mathrm{Si} / \mathrm{Si}$ and Dy-Si/Si delivered equivalent capacities at the 1000th cycle to the $\mathrm{La}-\mathrm{Si} / \mathrm{Si}$ electrode, which are inferior to the performance of the $\mathrm{Gd}-\mathrm{Si} / \mathrm{Si}$ electrode.

To evaluate the contribution of these silicides to the composite electrodes' capacities, we synthesized silicide electrodes composed of $\mathrm{Sm}-\mathrm{Si}, \mathrm{Gd}-\mathrm{Si}$, and Dy-Si. These silicide electrodes showed very small capacities of around several ten $\mathrm{mA} \mathrm{h} \mathrm{g}{ }^{-1}$ though the capacities stably maintained for a long cycle (Fig.S5), as in the case of La-Si electrodes [14,15]. This indicates that the composite electrodes derive nearly all capacities not from silicides but from elemental Si.

The excellent performance of this electrode promises to exhibit a good high-rate performance also. Figure 3 displays a rate performance of the $\mathrm{Gd}-\mathrm{Si} / \mathrm{Si}$ thick-film electrode. The composite electrodes contained approximately $70 \mathrm{wt} . \%$ elemental $\mathrm{Si}$. Thus, the discharge capacities have been converted to capacities per weight of elemental $\mathrm{Si}$ in this figure. The $\mathrm{Gd}-\mathrm{Si} / \mathrm{Si}$ composite exhibited a better high-rate performance compared with $\mathrm{Sm}-\mathrm{Si} / \mathrm{Si}$, Dy-Si/Si, and Si alone. Very large capacities of about $2100 \mathrm{~mA} \mathrm{~h} \mathrm{~g}^{-1}$ sustained even at a high rate of $12.0 \mathrm{~A} \mathrm{~g}^{-1}$ (4.8C). In these days, Ai et al. have prepared $\mathrm{FeSi} / \mathrm{Si}$ composite electrodes by a two-step ball-milling process, and have reported that the $\mathrm{FeSi} / \mathrm{Si}$ composites delivered the capacity of $700 \mathrm{~mA} \mathrm{~h} \mathrm{~g}^{-1}$ at a current density of $1.0 \mathrm{~A} \mathrm{~g}^{-1}$ [11]. As a further advanced anode, Guo et al. have succeeded to synthesize $\mathrm{Si}-\mathrm{Al}_{2} \mathrm{O}_{3}$ composite electrodes on nanopillar $\mathrm{Cu}$ substrate by using a magnetron sputtering, an atomic layer deposition, and a successive thermal treatment in a reducing atmosphere. The composite electrode exhibited a superb high-rate performance with the capacity of $1500 \mathrm{~mA} \mathrm{~h} \mathrm{~g}$ at $2.8 \mathrm{~A}$ $\mathrm{g}^{-1}$ [28]. Our Gd-Si/Si thick-film electrode exerted much larger capacities even at a four times higher rate compared with their nanopillar $\mathrm{Si}_{-} \mathrm{Al}_{2} \mathrm{O}_{3}$ anodes, which obviously demonstrates an excellent high-rate performance of the electrode. The results of this study offer possibilities of novel anode materials based on rare-earth element silicides combining a high capacity, a stable cyclability, and an excellent high-rate performance. To discuss a reason for the improved performance by $\mathrm{Gd}-\mathrm{Si}$ is beyond the scope of a brief 
paper because the detailed mechanism underlying the improvement is still unclear. Electrical conductivity for powder of $L n-S i$ was measured under a uniaxial press using a two probes method [16]. We confirmed that $\mathrm{Ln}-\mathrm{Si}$ showed three orders of magnitude higher conductivity compared with $\mathrm{Si}$, and that there was no difference in the conductivity among the rare-earth metal silicides (Table S1). We, therefore, propose a hypothesis with mechanical property: the gadolinium silicide has a more elastic property in comparison with other silicides (Fig.S6), and thus the silicide releases more effectively the stress from Si.

\section{Summary}

The composite thick-film electrodes consisted of elemental $\mathrm{Si}$ and rare-earth metal silicides, $\mathrm{Sm}-\mathrm{Si}$, $\mathrm{Gd}-\mathrm{Si}$, and $\mathrm{Dy}-\mathrm{Si}$, were prepared for Li-ion battery anodes by the arc melting method and the successive gas-deposition method. Among them, the $\mathrm{Gd}-\mathrm{Si} / \mathrm{Si}$ composite electrode exhibited the most excellent performance: the initial Coulombic efficiency was as high as $80 \%$ and the discharge capacity at the 1000th cycle was $840 \mathrm{~mA} \mathrm{~h} \mathrm{~g}^{-1}$. The composite electrode delivered a superb high-rate performance with the capacity of $2100 \mathrm{~mA} \mathrm{~h} \mathrm{~g}^{-1}$ even at $12.0 \mathrm{~A} \mathrm{~g}^{-1}$. We believe that rare-earth metal silicide is also ideal standard material for the next-generation anodes of Li-ion battery with a high capacity and a rapid charging property because of its excellent anode performance.

\section{Acknowledgments}

This work has been supported in part by the Li-EAD program of the New Energy and Industrial Technology Development Organization (NEDO) of Japan. This work has been partially supported by Japan Society for the Promotion of Science (JSPS) KAKENHI, Grant-in-Aid for Scientific Research (B) (Grant Number 24350094). 


\section{References}

[1] T. D. Hatchard and J. R. Dahn, J. Electrochem. Soc., 151, (2004) A838.

[2] M. N. Obrovac and L. Christensen, Electrochem. Solid-State Lett., 7 (2004) A93.

[3] M. N Obrovac. and L. J. Krause, J. Electrochem. Soc., 154 (2007) A103.

[4] G. A. Roberts, E. J. Cairns, J. A. Reimer, J. Power Sources, 110 (2002) 424.

[5] A. Netz, R. A. Huggins, W. Weppner, J. Power Sources, 119-121 (2003) 95.

[6] J. Wolfenstine, J. Power Sources, 124 (2003) 241.

[7] S. Zhou, D. Wang, ACS Nano, 4 (2010) 7014.

[8] H. Usui, T. Yoneda, M. Ono, H. Sakaguchi, Abstract 1383, presented at the 220th ECS Meeting and Electrochemical Energy Summit, Boston, MA (2011).

[9] F. M. Courtel, D. Duguay, Y. Abu-Lebdeh, I. J. Davidson, J. Power Sources, 202 (2012) 269.

[10] J.-A. Choi, D.-W. Kim, Y.-S. Bae, S.-W. Song, S.-H. Hong, S.-M. Lee, Electrochim. Acta, 56 (2011) 9818.

[11] Y. Chen, J. Qian, Y. Cao, H. Yang, X. Ai, ACS Appl. Mater. Interfaces, 4 (2012) 3753.

[12] Y.-L. Kim, H.-Y. Lee, S.-W. Jang, S.-H. Lim, S.-J. Lee, H.-K. Baik, Y.-S. Yoon, S.-M. Lee, Electrochim. Acta, 48 (2003) 2593.

[13] A. Netz, R. A. Huggins, W. Weppner, Ionics, 7 (2001) 433.

[14] T. Hirono, M. Ito, T. Iida, H. Sakaguchi, Abstract 74, presented at the 214th ECS meeting, Honolulu, Hawaii (2008).

[15] H. Sakaguchi, T. Iida, M. Itoh, N. Shibamura, T. Hirono, IOP Conf. Series: Mater. Sci. Eng., 1 (2009) 012030.

[16] H. Usui, K. Meabara, K. Nakai, H. Sakaguchi, Int. J. Electrochem. Sci., 6 (2011) 2246.

[17] H. Usui, M. Shimizu, H. Sakaguchi, J. Power Sources, 235 (2013) 29.

[18] H. Nishino, H. Usui, M. Kusatsu, T. Murota, H. Sakaguchi, Abstract P-17, presented at International Symposium Rare Earths, Naha, Japan (2012).

[19] S. Auffret, J. Pierre, B. Lambert-Andron, R. Madar, E. Houssay, D. Schmitt, E. Siaud, Physica B, 173 (1991) 265.

[20] P. Demchenko, O. Bodak, L. Muratova, J. Alloys Compd., 346 (2002) 170.

[21] H. Sakaguchi, T. Toda, Y. Nagao, T. Esaka, Electrochem. Solid-State Lett., 10 (2007) J146. 
[22] H. Usui, Y. Kiri, H. Sakaguchi, Thin Solid Films, 520 (2012) 7006.

[23] Y.-M. Kang, S.-M. Lee, S.-J. Kim, G.-J. Jeong, M.-S. Sung, W.-U. Choi, S.-S. Kim, Electrochem. Commun., 9 (2007) 959.

[24] V. L. Chevrier, J. W. Zwanziger, J. R. Dahn, J. Alloys Compd., 496 (2010) 25.

[25] M. K. Datt, P. N. Kumta, J. Power Sources, 194 (2009) 1043.

[26] S. Misra, N. Liu, J. Nelson, S. S. Hong, Y. Cui, M. F. Toney, ACS Nano, 6 (2012) 5465.

[27] H. Nakamura, H. Komatsu, M. Yoshio, J. Power Sources, 62 (1996) 219.

[28] F.-F. Cao, J.-W. Deng, S. Xin, H.-X. Ji, O. G. Schmidt, L.-J. Wan, Y.-G. Guo, Adv. Funct. Mater., 23 (2011) 4415.

\section{Figure captions}

Table 1. Summary of crystal phases and anode performances for thick-film electrodes consisted of rare-earth metal silicides $(\mathrm{Ln}-\mathrm{Si})$ and $\mathrm{Si}$. Only $\mathrm{La}-\mathrm{Si} / \mathrm{Si}$ composite was synthesized by mechanical alloying method [15].

Figure 1. Initial charge-discharge curves of composite thick-film electrodes consisted of rare-earth metal silicides and elemental Si. Values in parentheses indicate initial Coulombic efficiencies.

Figure 2. Variation in discharge capacities as a function of charge-discharge cycle number for various composite electrodes of rare-earth metal silicides and elemental $\mathrm{Si}$.

Figure 3. High-rate anode performance of $\mathrm{Gd}-\mathrm{Si} / \mathrm{Si}$ composite electrodes in $\mathrm{LiClO}_{4} /$ propylene carbonate electrolyte. The charge-discharge current density was varied from $1.2 C\left(3.0 \mathrm{~A} \mathrm{~g}^{-1}\right)$ to $4.8 C\left(12.0 \mathrm{~A} \mathrm{~g}^{-1}\right)$. Discharge capacities of composite electrodes were converted to capacities per weight of elemental Si. 


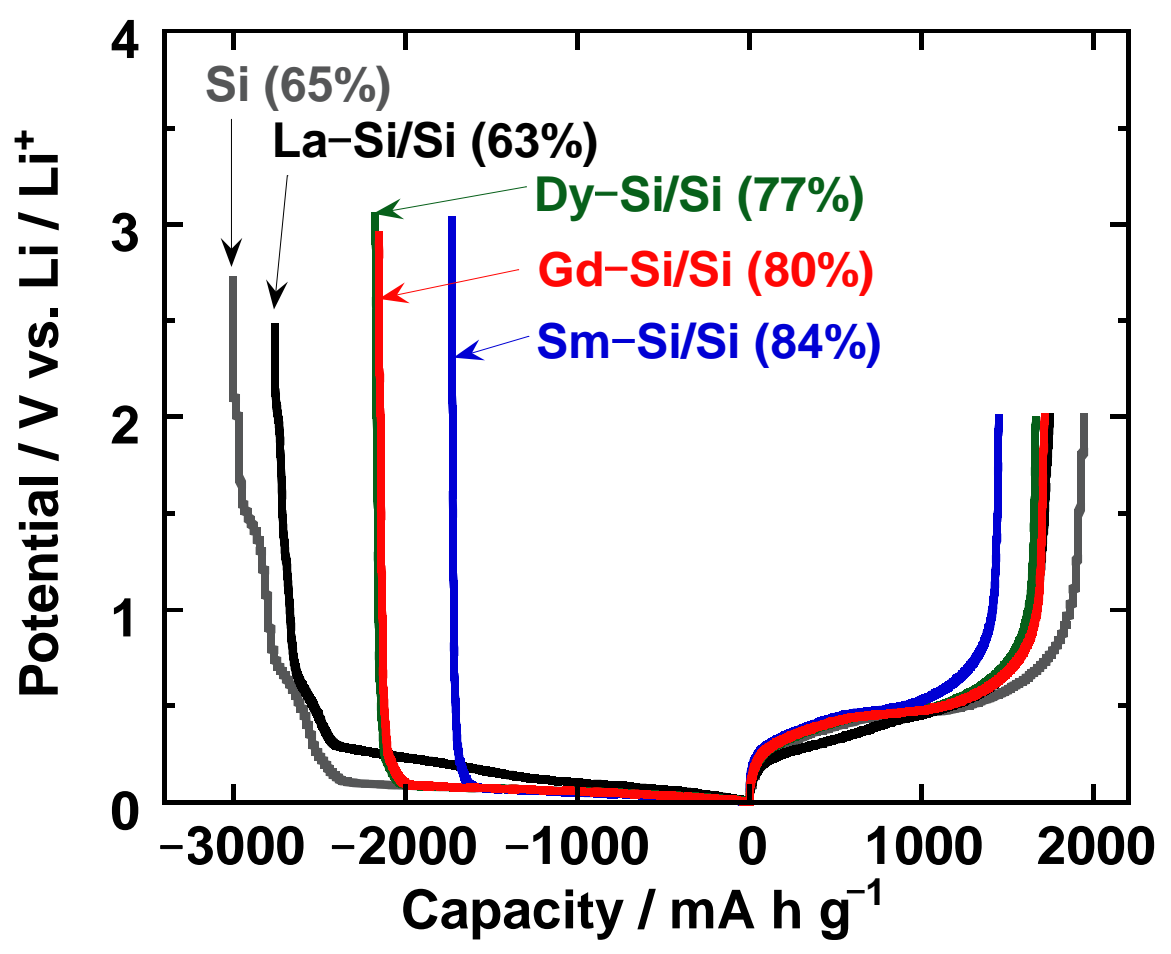

Figure 1. Initial charge-discharge curves of composite thick-film electrodes consisted of rare-earth metal silicides and elemental Si. Values in parentheses indicate initial Coulombic efficiencies.

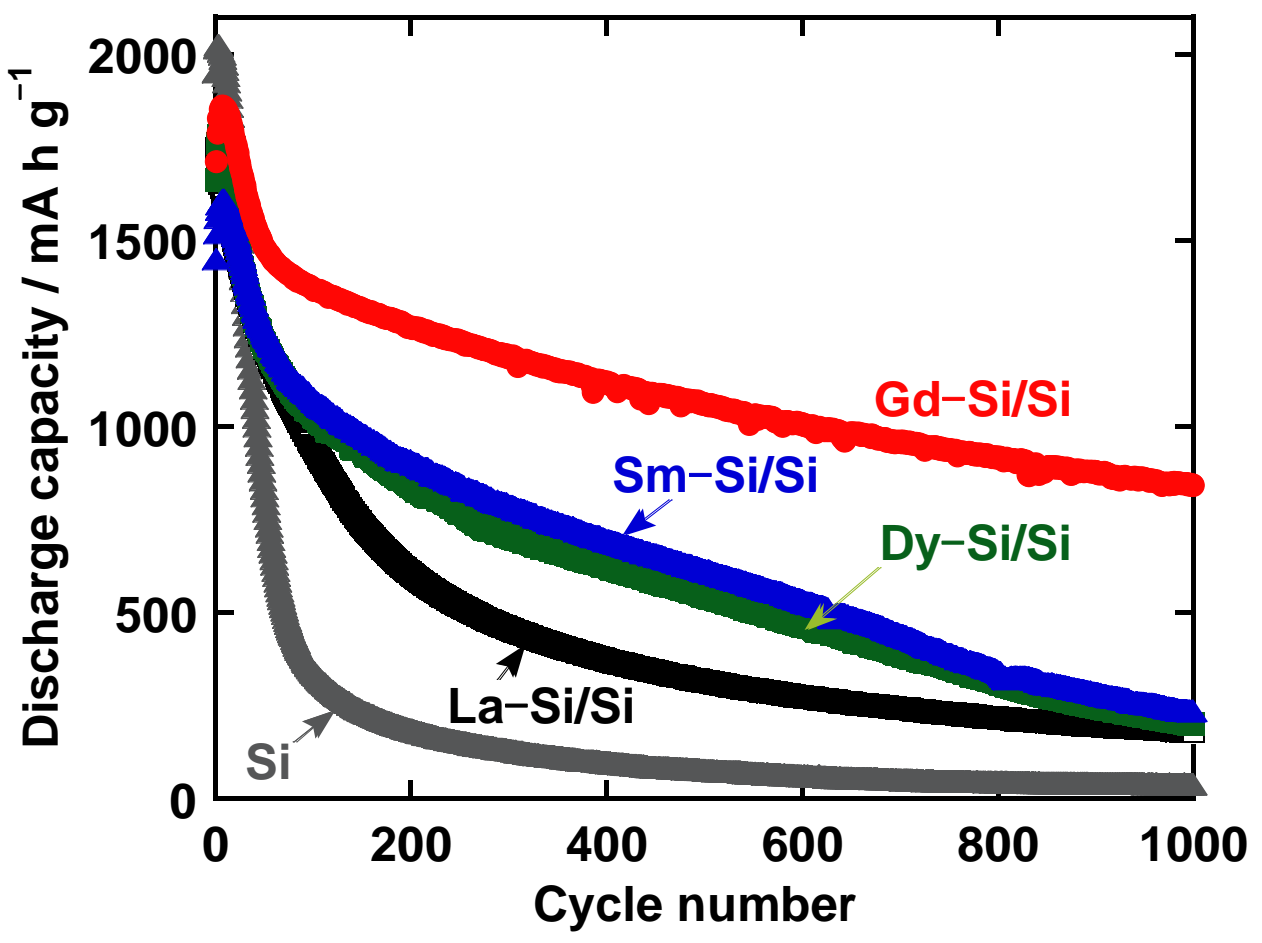

Figure 2. Variation in discharge capacities as a function of charge-discharge cycle number for various composite electrodes of rare-earth metal silicides and elemental Si. 


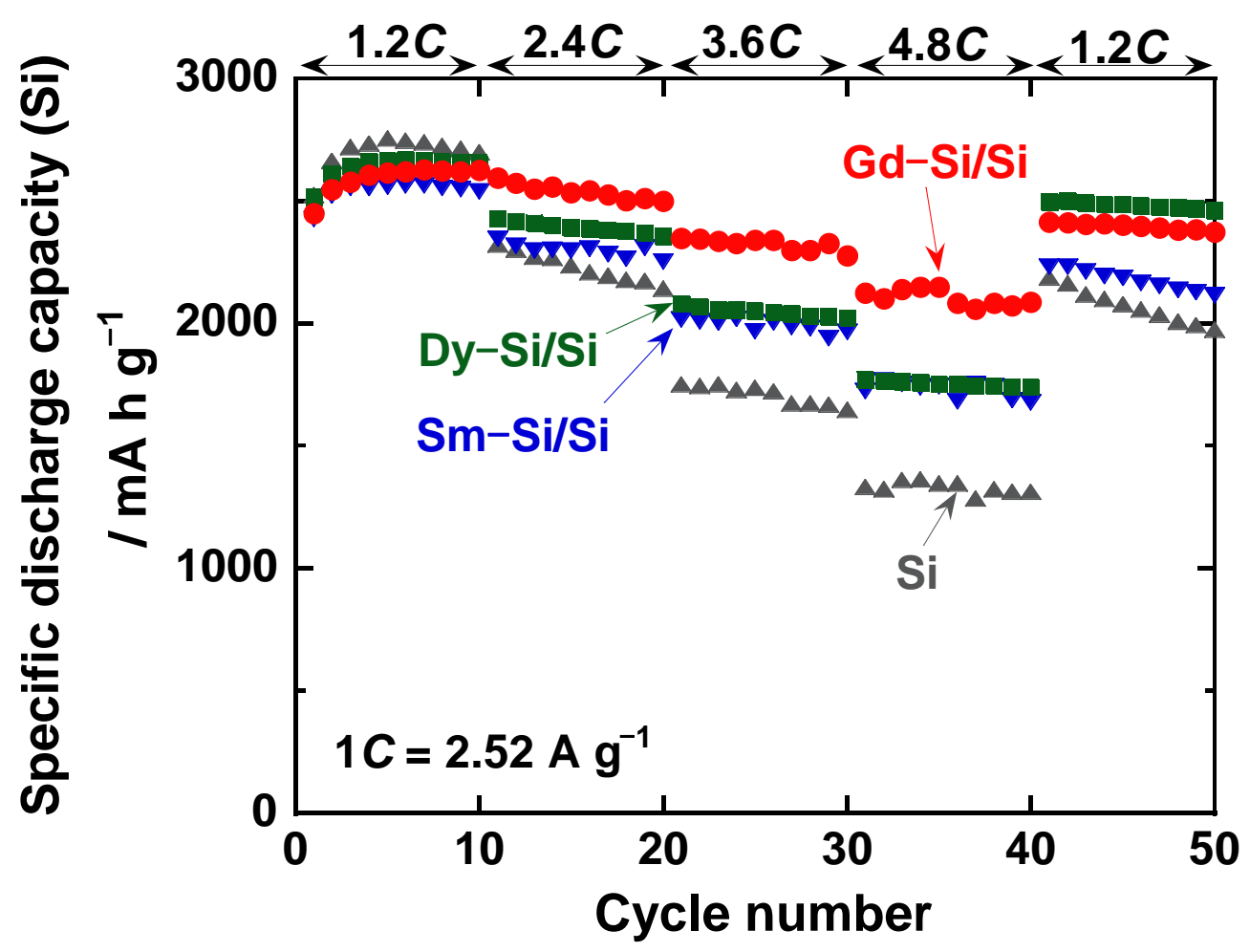

Figure 3. High-rate anode performance of Gd-Si/Si composite electrodes in $\mathrm{LiClO}_{4} /$ propylene carbonate electrolyte. The charge-discharge current density was varied from $1.2 \mathrm{C}\left(3.0 \mathrm{~A} \mathrm{~g}^{-1}\right)$ to $4.8 \mathrm{C}\left(12.0 \mathrm{~A} \mathrm{~g}^{-1}\right)$. Discharge capacities of composite electrodes were converted to capacities per weight of elemental $\mathrm{Si}$.

Table 1. Summary of crystal phases and anode performances for thick-film electrodes consisted of rare-earth metal silicides ( $L n-\mathrm{Si}$ ) and Si. Only La-Si/Si composite was synthesized by mechanical alloying method [15].

\begin{tabular}{|c|c|c|c|c|c|}
\hline \multirow[t]{2}{*}{ Sample } & \multirow{2}{*}{$\begin{array}{c}\text { Crystal phase } \\
\text { of } L n-S i \\
\text { (ICSD. No) }\end{array}$} & \multicolumn{2}{|c|}{$\begin{array}{c}\text { Weight ratio of } \\
\text { Ln-Si : Si composite } \\
\text { / wt.\% }\end{array}$} & \multicolumn{2}{|c|}{$\begin{array}{l}\text { Discharge capacity } \\
\qquad / \mathrm{mA} \mathrm{h} \mathrm{g}^{-1}\end{array}$} \\
\hline & & $L n-S i$ & $\mathrm{Si}$ & 1st & 1000th \\
\hline La-Si/Si & $\begin{array}{c}\mathrm{LaSi}_{2} \\
(01-074-0230)\end{array}$ & 30 & 70 & 1740 & 170 \\
\hline $\mathrm{Sm}-\mathrm{Si} / / \mathrm{Si}$ & $\begin{array}{c}\mathrm{SmSi}_{2} \\
(00-048-1621)\end{array}$ & 30 & 70 & 1440 & 230 \\
\hline $\mathrm{Gd}-\mathrm{Si} / \mathrm{Si}$ & $\begin{array}{c}\mathrm{GdSi}_{1.85} \\
(01-070-9008)\end{array}$ & 28 & 72 & 1710 & 840 \\
\hline Dy-Si/Si & $\begin{array}{c}\text { DySi }_{1.75} \\
(03-065-7247)\end{array}$ & 29 & 71 & 1660 & 200 \\
\hline
\end{tabular}

